Maximize Your Spirometry Screening and Surveillance Resources

Spirometry is a common type of pulmonary function test

(PFT) that measures how well a person can move air in and

out of their lungs. In occupational settings, spirometry can

be used to establish a baseline before assigning a worker to job tasks that are physically demanding, that require use of a respirator, or that may expose the worker to respiratory

hazards. It is also used to track lung function over time and to evaluate workers who experience signs or symptoms of respiratory disease.

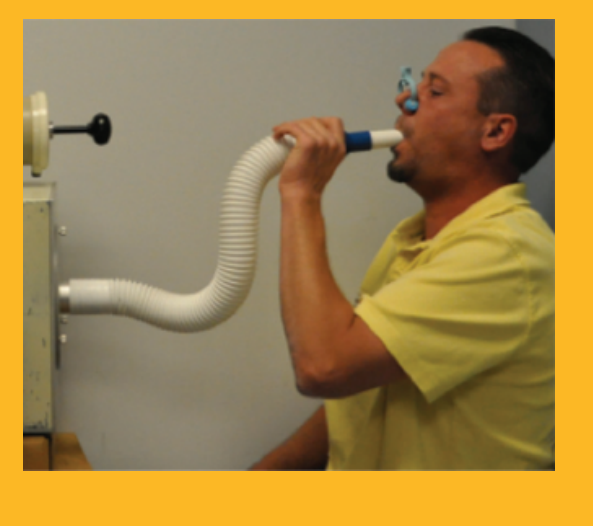

The Need for Spirometry Testing

Spirometry testing is required for some workers by OSHA standards. Accurate spirometry testing, interpretation, and follow-up are critical to effective screening and surveillance of workers exposed to respiratory hazards. Technically poor spirometry is of little value to the purchaser of these services and may provide misleading information.

\section{Technician Training}

Spirometry technicians should have a valid certificate from a National Institute for Occupational Safety and Health (NIOSH)-approved course or an equivalent training course. For more information go to:

www.cdc.gov/niosh/topics/spirometry/training.html.

\section{Spirometry Equipment}

The spirometry equipment and software used in such testing should be validated by independent laboratory testing documented by the manufacturer and should comply with the most recent American Thoracic Society/European Respiratory Society standards. Spirometry results should be computerized and the computer file kept by the healthcare provider. Spirometry technicians should check the calibration of the spirometer before use each day and keep calibration records as long as the related health records are retained. The spirometry technician and the healthcare professional are responsible for reviewing the spirometry results, checking validation criteria, and informing the employer of any equipment malfunctions.

\section{Frequency of Testing}

Periodic spirometry tests must be performed in accord with OSHA standards. For occupational exposures to substances for which no OSHA standard applies, periodic spirometry is usually recommended, although such testing can be done more or less frequently to evaluate changes in lung function over time. Testing less frequently than every 3 years is not recommended. The frequency of testing should be determined by the applicable OSHA standard or, where no standard applies, by the specific hazard to which workers are being exposed.

\section{Screening and Surveillance}

Periodic spirometry screening of individual workers can detect breathing problems or significant changes in lung function at an early stage so that hazardous workplace exposures can be identified and eliminated to prevent or reduce occupational lung disease. Equally important, surveillance can detect changes in lung function over time among groups of workers with similar exposures and thus help to recognize serious health effects in the workplace at a time when individual results may not be severe or noticeable. Employers should consider periodically reviewing grouped data from worksite exposure assessments with a healthcare professional and should be alert for any significant changes in grouped results. Reviewing grouped data may help identify occupational exposures and assist in reducing or eliminating any hazards identified. Additional resources on monitoring spirometry data over time in individuals or groups of workers can be found at:

www.cdc.gov/niosh/topics/spirometry/spirola.html.

The healthcare professional should analyze baseline and periodic spirometry test results and explain all results to the worker. The healthcare professional should determine when a spirometry test result indicates that the worker needs further medical evaluation. Finally, the healthcare professional should notify the employer if there are any concerns about occupational exposures while maintaining the confidentiality of worker health information. 


\section{Checklist for Employers}

Critical elements of spirometry testing that maximize your company's resources and should be considered for inclusion in required contracts include:

\section{Technicians and Clinical Healthcare Professionals}

Technicians who perform testing should have successfully completed a National Institute for Occupational Safety and Health (NIOSH)-approved course, or equivalent, within the past 5 years. $A$ certificate should be available for you to inspect.

The program should be supervised by a healthcare professional knowledgeable about spirometry accuracy and test validity. Documentation of the professional's spirometry update training should be available.

\section{Spirometry Equipment}

A letter from the spirometer manufacturer indicating successful validation testing of the spirometer, following current American Thoracic Society/ European Respiratory Society standards, should be available for review.

The spirometer's calibration is checked by the technician each day of use. Records of daily spirometer calibration checks should be maintained and available for review.

\section{Interpretation of Results}

Worker's results are compared to normal values. The report should specify the source of the normal or predicted values. If the testing satisfies a regulatory requirement, then the appropriate predicted values must be used.

Current worker's results are compared to his or her previous baseline values, if available. This is the preferred method of evaluating change over time.

\section{Reporting of Results}

The healthcare professional reports the results to the worker indicating how the worker's results compared to the normal range and whether changes over time require further medical evaluation.

\section{Resources}

For more information about spirometry screening, surveillance, and training visit OSHA online at www.osha.gov/SLTC/medicalsurveillance/index.html and www.osha.gov/Publications/osha3162.pdf (Screening and Surveillance: A Guide to OSHA Standards) and NIOSH online at: www.cdc.gov/niosh/topics/spirometry/default.html. Other helpful references that present the American College of Occupational and Environmental Medicine's position on Occupational Spirometry are: Townsend, MC. ACOEM position statement. Spirometry in the occupational setting. American College of Occupational and Environmental Medicine. J Occup Environ Med. 2000 Mar;42(3):228-45. and Townsend, MC. ACOEM Position Statement Spirometry in the Occupational Health Setting2010 Update at: www.acoem.org/uploadedFiles/ Public_Affairs/Policies_And_Position_Statements/ ACOEM\%20Spirometry\%20Statement.pdf.

\section{OSHA Publications}

OSHA has an extensive publications program. For a listing of free items, visit OSHA's web site at www.osha.gov/publications or contact the OSHA Publications Office, U.S. Department of Labor, 200 Constitution Avenue, N.W., N-3101, Washington, DC 20210. Telephone (202) 693-1888 or fax to (202) 693-2498.

\section{Contacting OSHA}

To report an emergency, file a complaint or seek OSHA advice, assistance or products, call (800) 321-OSHA or contact your nearest OSHA regional, area, or State Plan office; TTY: 1-877-889-5627.

\section{Contacting NIOSH}

To receive documents or more information about occupational safety and health topics, please contact NIOSH: 1-800-CDC-INFO (1-800-232-4636); TYY: 1-888-232-6348; e-mail: cdcinfo@cdc.gov or visit the NIOSH web site at www.cdc.gov/niosh.

This guidance document is not an OSHA standard or regulation but contains recommendations that are advisory in nature and intended to assist employers in providing a safe and healthful workplace. The mention of any nongovernmental organization or link to its web site in this guidance does not constitute an endorsement by NIOSH or OSHA of that organization, its products or services or web site.

For more complete information:
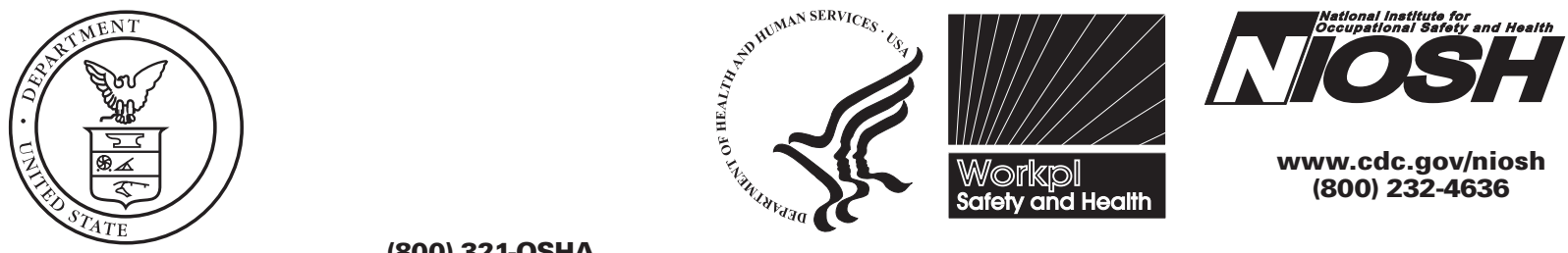

(800) 321-OSHA 